\title{
Clinical Notes Generation Application
}

\author{
Prashant Kanade \\ Assistant Professor \\ Department of Computer \\ Engineering \\ VESIT
}

\author{
Kunal Chugriya \\ Student \\ Department of Computer \\ Engineering \\ VESIT
}

\author{
Meetali Dulera \\ Student \\ Department of Computer \\ Engineering \\ VESIT
}

\author{
Vrudhi Israni \\ Student \\ Department of Computer \\ Engineering \\ VESIT
}

\author{
Rahul Tejwani \\ Student \\ Department of Computer \\ Engineering \\ VESIT
}

\begin{abstract}
In today's world, having a doctor to write notes and prescriptions would waste a lot of time. Hence, to resolve this we aim on preparing a software which will aid the doctor in noting down important details of the patient along with date and time records by converting speech to text. This app will contain a glossary of medical terms so that the obtained text is error free. This will not only save the doctor's time and effort, but also provide the patient reports faster which will in turn help them to continue the treatment faster. This is a helping hand to all the health workers who have to otherwise spend hours digitizing the handwritten reports. When there are more than one person working on a clinical note, the error rate can be higher if the other person is not able to decipher their handwriting. This can cause a great deal of problem if it leads to a change in the medical dosage given to the patient. In order to improve the work at hospitals and clinicals we have implemented this clinical notes generation software which converts the doctor's voice to text and generates clinical notes for the patients.
\end{abstract}

\section{Keywords}

Mobile applications, Medical, Clinical Notes, Speech to Text.

\section{INTRODUCTION}

The objective of our project is to make a software that helps to generate clinical notes during surgeries/operations by converting voice to text. It would save time of writing down the notes and avoid paperwork. In today's world, having a doctor to write notes and prescriptions would waste a lot of time. Hence, to resolve this we aim on preparing a software which will aid the doctor in noting down important details of the patient along with date and time records by converting speech to text. This app will contain a glossary of medical terms so that the obtained text is error free. This software will save time of writing down the notes and will avoid paperwork. It converts the generated clinical note into a pdf format which makes it easy to share. Our project will have various templates of clinical notes available. The doctor can choose the template that the patient requires and generate the clinical note easily. An easy and efficient method to generate clinical notes. This will not only save the doctor's time and effort, but also provide the patient reports faster which will in turn help them to continue the treatment faster. This is a helping hand to all the health workers who have to otherwise spend hours digitizing the handwritten reports. When there is more than one person working on a clinical note, the error rate can be higher if the other person is not able to decipher their handwriting. This can cause a great deal of problem if it leads to a change in the medical dosage given to the patient. In order to improve the work at hospitals and clinicals we have implemented this clinical notes generation software which converts the doctor's voice to text and generates clinical notes for the patients.

\section{EXISTING SYSTEM}

Medical devices and apps are already invaluable tools for HCPs, and as their features and uses expand, they are expected to become even more widely incorporated into nearly every aspect of clinical practice. However, some HCPs remain reluctant to adopt their use in clinical practice. Although medical devices and apps inarguably provide the HCP with many advantages, they are currently being used without a thorough understanding of their associated risks and benefits. Rigorous evaluation, validation, and the development of best-practice standards for medical apps are greatly needed to ensure a fundamental level of quality and safety when these tools are used. With the implementation of such measures, the main determinant of our app's value may ultimately be its ability to provide meaningful, accurate, and timely information and guidance to the end user in order to serve the vital purpose of improving patient outcomes.

\section{PROJECT MOTIVATION}

This application will not only save the doctor's time and effort, but also provide the patient reports faster which will in turn help them to continue the treatment faster. This is a helping hand to all the health workers who have to otherwise spend hours digitizing the handwritten reports. When there is more than one person working on a clinical note, the error rate can be higher if the other person is not able to decipher their handwriting. This can cause a great deal of problem if it leads to a change in the medical dosage given to the patient. In order to improve the work at hospitals and clinicals we have implemented this clinical notes generation software

\section{PROPOSED SYSTEM}

We plan to make an application/software that helps to generate clinical notes during surgeries/operations by converting voice to text using google APIs and android studio. This software will save time of writing down the notes and will avoid paperwork. It converts the generated clinical note 
into a pdf format which makes it easy to share. Our project will have various templates of clinical notes available. The doctor can choose the template that the patient requires and generate the clinical note easily. An easy and efficient method to generate clinical notes. The application will be made using android studio. Android studio helps in making applications with ease. We will prepare a user friendly front end for our application using android studio. For the backend database and login authentication we will use Firebase. And for our main speech to text and text to speech conversions we will use Google APIs like gTTS. We will create a smooth functioning application that helps in the medical sector.

\section{APPLICATION FEATURES}

- Administrator Login

- Voice to text system
- Date and Time of the report will be recorded

- Abnormal readings can be marked with a different color.

- Database system to store all the recordings safe and systematically.

- Different accounts for different doctors to record readings of their respective patients.

- Password protection to ensure security and to prevent data from being manipulated.

- Sharing options available for easily sharing the report with other doctors/surgeons/dieticians.

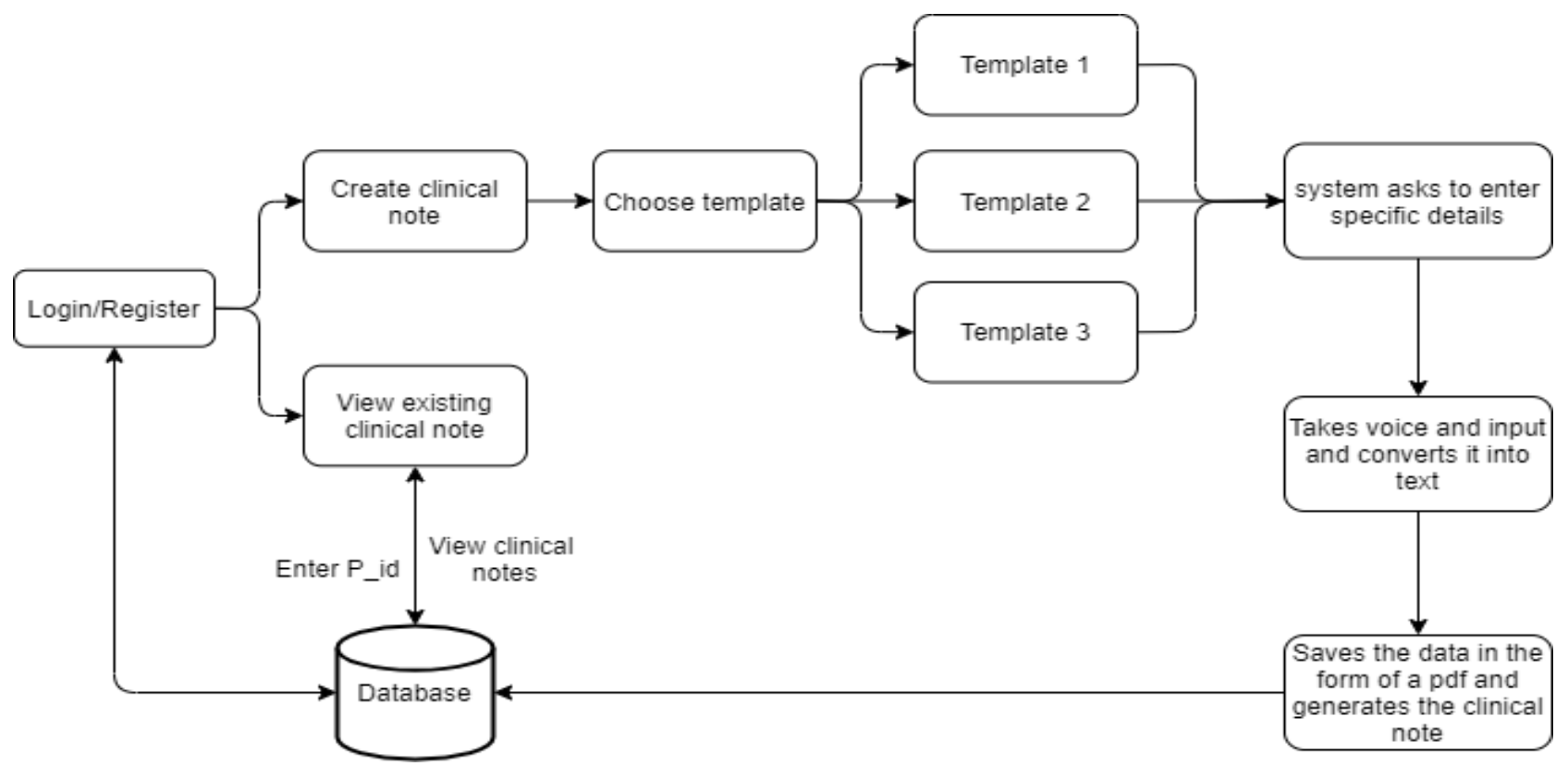

Fig 1: Block Diagram of the application

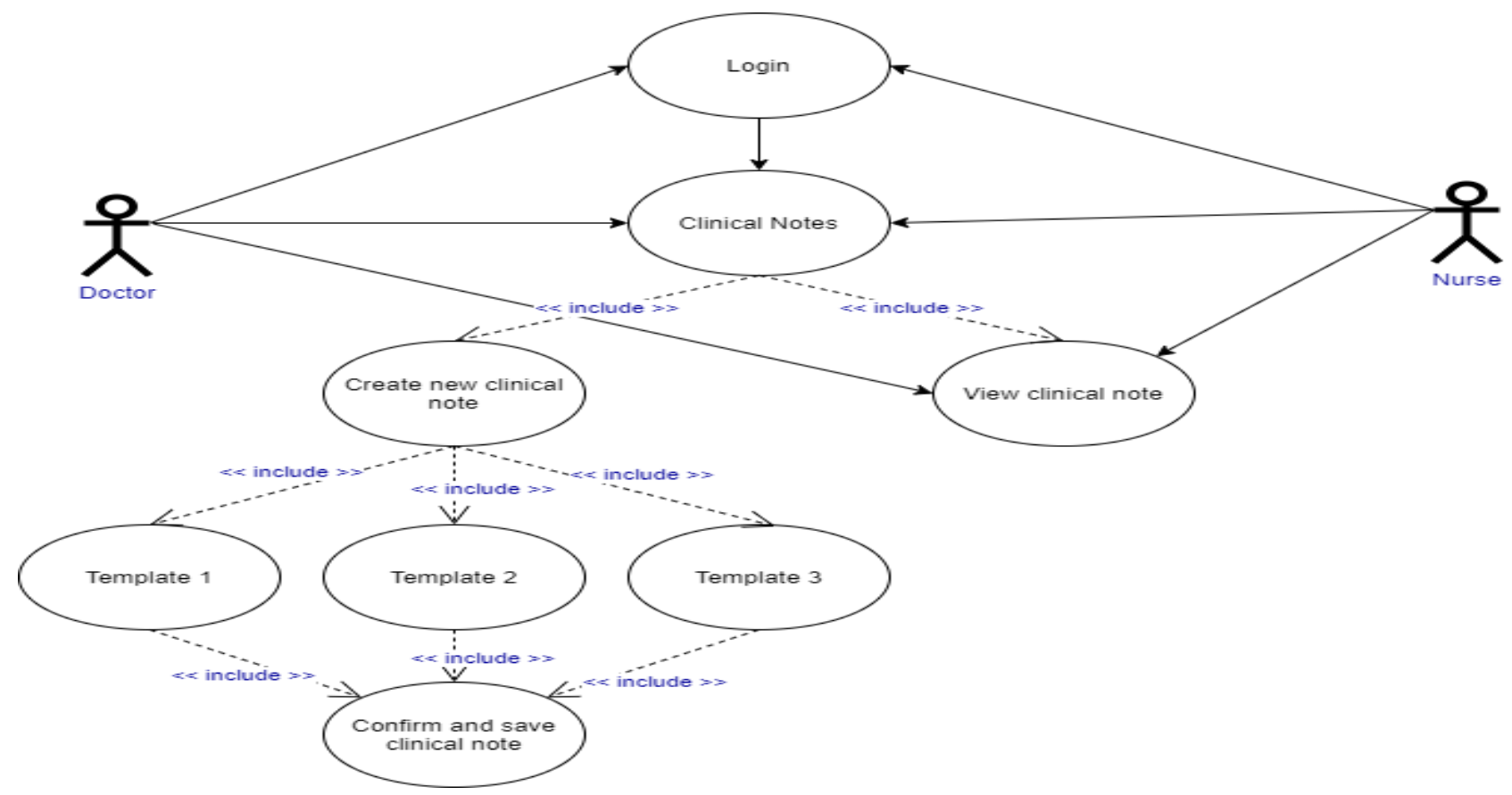

Fig 2. UML Diagram 


\section{METHODOLOGY EMPLOYED}

Android studio was used to create the complete front end of the application. Firebase for the login and authentication for the application. For the speech to text and text to speech conversion we have used Google APIs. Google APIs are very fast and reliable for speech to text and text to speech conversion. The steps or the methodology used to make our application included the following steps.

- Define the problem.

- Measure in detail the various aspects of the current process.

- Analyze data to, among other things, find the root defects in a process.

- Improve the process.

- Control how the process is done in the future.

- Define the project goals.

- Measure critical components of the process and the product capabilities.

- Analyze the data and develop various designs for the process, eventually picking the best one.

- Design and test details of the process.

- Verify the design by running simulations and a pilot program, and then handing over the process to the client.

\section{TESTING}

\subsection{Test Cases}

The different test cases used to test our application are given below. We chose the test cases such that we are able to evaluate every process/task that our application performs. We tested each case several times until we were able to analyse the errors or glitches accurately.

Test case 1: Sign Up

Test case 2: Login

Test case 3: Choosing task

Test case 4: Selecting Clinical note template

Test case 5: Entering information by converting voice to text

Test case 6: Converting generated clinical note into a pdf

Test case 7: Viewing generated clinical notes by entering sufficient data

Test case 8: Testing accuracy of the word converted from voice to text

Test case 9: Logging out of the application successfully

Test case 10: Testing the GUI of the application

\subsection{Test Analysis}

\begin{tabular}{|c|c|c|}
\hline Test case & Description & Result \\
\hline $\mathbf{1}$ & Sign Up & $\begin{array}{c}\text { The application allowed the user } \\
\text { to enter sufficient information and } \\
\text { sign up to the app successfully } \\
\text { without any issues. }\end{array}$ \\
\hline
\end{tabular}

\begin{tabular}{|c|c|c|}
\hline 2 & Login & $\begin{array}{l}\text { The application's login function is } \\
\text { running smoothly. }\end{array}$ \\
\hline 3 & Choosing task & $\begin{array}{l}\text { The buttons work well and take } \\
\text { the user to the page which he } \\
\text { wishes to work on. }\end{array}$ \\
\hline 4 & $\begin{array}{l}\text { Selecting } \\
\text { Clinical note } \\
\text { template }\end{array}$ & $\begin{array}{l}\text { The radio buttons allow the user to } \\
\text { select the template which is best } \\
\text { suited by the patient. They work } \\
\text { well without errors. }\end{array}$ \\
\hline 5 & $\begin{array}{l}\text { Entering } \\
\text { information by } \\
\text { converting } \\
\text { voice to text }\end{array}$ & $\begin{array}{l}\text { The voice to text function and the } \\
\text { text to voice function work } \\
\text { smoothly and help the doctor to } \\
\text { create clinical notes with ease. }\end{array}$ \\
\hline 6 & $\begin{array}{l}\text { Converting } \\
\text { generated } \\
\text { clinical note } \\
\text { into a pdf }\end{array}$ & $\begin{array}{l}\text { Once the clinical note has been } \\
\text { generated, the system successfully } \\
\text { converts it and saves it in the form } \\
\text { of a PDF which can easily be } \\
\text { printed or shared among other } \\
\text { doctors. }\end{array}$ \\
\hline 7 & $\begin{array}{l}\text { Viewing } \\
\text { generated } \\
\text { clinical notes } \\
\text { by entering } \\
\text { sufficient data }\end{array}$ & $\begin{array}{l}\text { To view an existing clinical note, } \\
\text { the doctor is asked to enter the } \\
\text { patient id and the clinical note } \\
\text { template. the system then searches } \\
\text { in the database for a clinical note } \\
\text { having these attributes. If it exists, } \\
\text { the doctor can view the note. }\end{array}$ \\
\hline 8 & $\begin{array}{l}\text { Testing } \\
\text { accuracy of the } \\
\text { word } \\
\text { converted from } \\
\text { voice to text }\end{array}$ & $\begin{array}{l}\text { The google API gTTS which } \\
\text { converts voice to text and text to } \\
\text { voice which we used in our } \\
\text { system has an accuracy rate of } \\
95 \% \text {. The error rate is merely } \\
4.7 \% \text {. This is almost as much as in } \\
\text { human conversations. }\end{array}$ \\
\hline 9 & $\begin{array}{l}\text { Logging out of } \\
\text { the application } \\
\text { successfully }\end{array}$ & $\begin{array}{l}\text { The logout button works well and } \\
\text { helps the user to logout. Once } \\
\text { logged out, the application cannot } \\
\text { be used until the person logs in } \\
\text { again. }\end{array}$ \\
\hline 10 & $\begin{array}{l}\text { Testing the } \\
\text { GUI of the } \\
\text { application }\end{array}$ & $\begin{array}{l}\text { The application is user friendly } \\
\text { and easy to operate. It runs } \\
\text { smoothly and without glitches. }\end{array}$ \\
\hline
\end{tabular}

\section{FUTURE SCOPES}

Some of the future scopes that can improve the overall experience of this application are as follows.

1. A feature to automatically detect abnormal medical readings and highlighting it.

2. Comparative analysis of all the reports of that patient. 
3. Voice recognition of different doctors so that they can login automatically.

4. Reducing the time gap.

5. Reducing error rate.

6. Making the system more user friendly.

7. Making the application more secure and threat free

\section{ACKNOWLEDGEMENT}

The Clinical notes generator mobile application is the idea inspired from several mobile applications dealing with managing the problems related to writing clinical notes of patients. Some of the applications that we would like to list are 75 Health, OpenEMR, Open MRS2 etc. all available in the android market. However, our application only inspires ideas and we implement them on our own by including some more unique features that make the application more useful to the user.

\section{CONCLUSION}

Traditional method of clinical notes generation requires a lot of time and it has a higher error rate which can be very dangerous for the health of the patient. Our system provides a user friendly platform for the doctors to generate clinical notes by converting speech to text. This saves time, is more efficient, reduces errors and improves the overall experience of generating clinical notes. It is also useful for comparative study and improvement in health. The speech to text conversion is very helpful as it makes the task effortless.

\section{REFERENCES}

[1] Li Zhou, MD, PhD "Analysis of Errors in Dictated Clinical Documents Assisted by Speech Recognition Software and Professional Transcriptionists." Published:
July 6, 2018. doi:10.1001/jamanetworkopen.2018.0530 .

[2] Thomas H Payne, W David Alonso, J Andrew Markiel, Kevin Lybarger, Ross Lordon, Meliha Yetisgen, Jennifer M Zech, Andrew A White "Using voice to create inpatient progress notes: effects on note timeliness, quality, and physician satisfaction" Published: 12 September 2018 JAMIA Open, Volume 1, Issue 2, October 2018, Pages 218-226

[3] Alexandre Alapetite, Henning Boje Andersen1, Morten Hertzum2 "Acceptance of Speech Recognition by Physicians: A Survey of Expectations, Experiences, and Social Influence" Published in international Journal of Human-Computer Studies January 2009

[4] Linder JA, Schnipper JL, Tsurikova R, Melnikas AJ, Volk LA, Middleton B. "Barriers to electronic health record use during patient visits" AMIA Annu Symp Proc 2006: 499-503

[5] Johnson KB, Cowan J. Clictate "A computer-based documentation tool for guideline-based care" J Med Syst 2002; 26(1): 47-60

[6] Ash JS, Berg M, Coiera E. Some unintended consequences of information technology in health care "The nature of patient care information system related errors" J Am Med Inform Assoc 2004; 11(2): 104-112

[7] Rosenbloom ST, Grande J, Geissbuhler A, Miller RA "Experience in implementing inpatient clinical note capture via a provider order entry system". J Am Med Inform Assoc 2004; 11(4): 310-315

[8] Giuse DA, Mickish A "Increasing the availability of the computerized patient record" Proc AMIA Annu Fall Symp 1996: 633-637 